\title{
Analysis of the use of microcystin-contaminated water in the growth and nutritional quality of the root-vegetable, Daucus carota
}

\author{
J. Machado ${ }^{1}$ - J. Azevedo ${ }^{1}$ - M. Freitas ${ }^{1,3}$ - E. Pinto ${ }^{2,3}$ - A. Almeida ${ }^{2}$. \\ V. Vasconcelos ${ }^{1,4}$ - A. Campos ${ }^{1}$
}

\begin{abstract}
Toxic cyanobacterial blooms are often observed in freshwaters and may reflect the increased eutrophication of these environments and alterations in climate. Cyanotoxins, such as microcystins (MCs), are an effective threat to many life forms, ranging from plants to humans. Despite the research conducted to date on cyanotoxins, the risks associated to the use of contaminated water in agriculture require further elucidation. To tackle this aim, a research was conducted with the root-vegetable Daucus carota. The specific aims of this work were the following: (i) to evaluate the effects of MC-LR on the plant growth and photosynthesis; (ii) to evaluate the nutritional quality of carrot roots; and (iii) to measure bioaccumulation. To this purpose, young carrots were grown in soil during 1 month in natural conditions and exposed to Mycrocystis aeruginosa aqueous extracts containing
\end{abstract}

A. Campos

acampos@ciimar.up.pt

1 Interdisciplinary Centre of Marine and Environmental Research (CIIMAR/CIMAR), University of Porto, Rua dos Bragas 289, P 4050-123 Porto, Portugal

2 REQUIMTE, Department of Chemical Sciences, Laboratory of Applied Chemistry, Faculty of Pharmacy, University of Porto, Rua de Jorge Viterbo Ferreira 228, P 4050-313 Porto, Portugal

3 Department of Environmental Health of School of Allied Health Technologies, and CISA/Research Center in Environment and Health, Polytechnic Institute of Porto, Rua de Valente Perfeito, 322, P 440-330 Gaia, Portugal

4 Department of Biology, Faculty of Sciences, University of Porto, Rua do Campo Alegre, P 4069-007 Porto, Portugal environmentally realistic concentrations of MC-LR (10 and $50 \mathrm{MC}-\mathrm{LR} \mu \mathrm{g} / \mathrm{L})$. The results showed that MC-LR may decrease root growth after 28 days of exposure to $50 \mu \mathrm{g} / \mathrm{L}$ and increase photosynthetic efficiency. We also observed changes in mineral and vitamin content in carrots as a result of the exposure to contaminated water. Moreover, MC-LR was detected in carrot roots by ELISA at very low concentration $5.23 \pm 0.47 \mathrm{ng}$ MC eq./g FW. The soil retained $52.7 \%$ of the toxin potentially available for plants. This result could be attributed to MC-LR adsorption by soil particles or due to microbial degradation of the toxin. We conclude that the prolonged use of MC-LR-contaminated water may affect crop growth, alter the nutritional value of vegetable products, and potentiate contamination.

Keywords Cyanobacteria · Irrigation water .

Microcystin-LR · Daucus carota · Growth · Vitamins ·

Minerals

\section{Introduction}

The intensification of agricultural and industrial activities in recent decades has caused several environmental problems such as the eutrophication of aquatic ecosystems (O'Neil et al., 2012). Associated to the eutrophication, outbreaks of harmful algal blooms (HABs) have become a major environmental threat worldwide. The frequency and intensity of HABs, including toxin-producing cyanobacteria, increased in the last decades limiting the use of the available water resources and may represent a risk to human health (Paerl and Paul, 2012). Among the cyanobacterial toxins, microcystins (MCs) are the most common cyanotoxins found worldwide (Funari and Testai, 2008). MCs, which have hepatotoxic activity, are small cyclic peptides that contain seven amino acids: two variable L- 
amino acids, three common D-amino acids or their derivatives, and two novel D-amino acids. These two D-amino acids are the 3S-amino-9S-methoxy-2,6,8S,-trimethyl-10-phenyldeca-4,6dienoic acid (Adda) and methyldehydroalanine (Mdha). Adda is characteristic of all structural MC congeners and is essential for their biological activity (Rao et al., 2002; Funari and Testai, 2008). Differences in amino acid composition and methylation patterns, and other less common chemical modifications, give rise to a diverse number of $\mathrm{MC}$ congeners. As such $\mathrm{MC}$ congeners also can differ in regard to their biological activity and toxicity (Dawson, 1998; Duy et al., 2000).

MCs have been found to be potent inhibitors of protein phosphatase 1 and 2A (PP1 and 2A) due to a covalent binding, being the liver the major target organ (Dawson, 1998; Hitzfeld et al., 2000). MCs are able to modulate the expression of oncogenes, proto-oncogenes, cytokines, and the tumor necrosis factor $\alpha(\mathrm{TNF} \alpha)$, affecting cell division, cell survival, and apoptosis (IARC, 2010). Several studies have also reported that MCs induce oxidative stress (Zegura et al., 2011, Huang et al., 2015, Zhou et al., 2015). Microcystin-LR (MC-LR), one of the most known cyanotoxin with leucine (L) and arginine (R) as variable L-amino acids (Figueiredo et al., 2004), is pointed as a possible tumor promoter, being classified by IARC (International Agency for Research on Cancer) as possible carcinogenic to humans (group 2B) (IARC, 2010). Indeed, some epidemiological studies have associated the exposure of humans to low doses of MCs with the increased incidence of hepatocellular carcinoma and colorectal cancer in certain areas of the globe (Yu, 1995; Ueno et al., 1996; Hitzfeld et al., 2000, Zhou et al., 2002).

The main route of human exposure to MC-LR is the ingestion of contaminated water and/or food. Fish food products are considered the main vectors of cyanotoxins (Hardy et al., 2015, Ni et al., 2015); nevertheless, toxin transfer may also occur with consumption of horticultural products. Indeed, several studies have already reported the accumulation of MCs in agricultural food products (Corbel et al., 2014a, RomeroOliva et al., 2014) and suggest the use of surface water contaminated with MC-LR as the main cause of contamination. Agricultural surface waters contaminated with MC-LR have been reported in countries such as Finland (Spoof et al., 2003), Spain (Aboal and Puig, 2005), Turkey (Gurbuz et al., 2009), Saudi Arabia (Mohamed and Al Shehri, 2009), China (Chen et al., 2012), Guatemala (Romero-Oliva et al., 2014), and Algeria (Nasri et al., 2008). These studies have shown that concentrations of MC-LR most frequently detected in the environment are in the range of 4 and $50 \mu \mathrm{g} / \mathrm{L}$; however, concentrations up to $29,000 \mu \mathrm{g} \mathrm{MC}-\mathrm{LR} / \mathrm{L}$ have been reported (Nasri et al., 2008). Moreover, the phytotoxic effects of MCLR on terrestrial plants have been suggested by different studies. Thus, it is important to point out the vulnerability of agricultural production systems, where contamination could potentially be responsible for reduced productivity and loss of quality of crop food products. MCs have shown to inhibit germination, decrease plant growth and crop yield, and alter chlorophyll content and photosynthesis (McElhiney et al., 2001; Pflugmacher, 2002; Gehringer et al., 2003; Chen et al., 2004; Pflugmacher et al., 2006, 2007b; Pereira et al., 2009; Saqrane et al., 2009; El Khalloufi et al., 2011). The induction of oxidative stress by the production of reactive oxygen species (ROS) seems to be another important biochemical mechanism of MC-LR toxicity in plants (Pflugmacher et al., 2006, 2007a, 2007b; Pichardo and Pflugmacher, 2011). Other studies point out for crop contamination with MCs (Peuthert et al., 2007; Crush et al., 2008; Saqrane et al., 2009) and nutritional changes (Saqrane et al., 2009; El Khalloufi et al., 2012; Lahrouni et al., 2013; Freitas et al., 2015). Notwithstanding, recent data suggest that many of the toxic effects are attenuated, or not verified, when plants are exposed to environmentally realistic toxin concentrations. Moreover, it has been recently shown that particular toxin exposure conditions may even boost plant development (Corbel et al., 2015, Freitas et al., 2015).

Carrots (Daucus carota) are root-vegetables with great importance for human nourishment and economy being extensively consumed worldwide (Singh et al., 2012). Since the plant root system is usually more exposed to water and soil contaminants, it is considered that root-vegetables may accumulate more contaminants than other leaf vegetables and crops, resulting in a less safe edible product. Despite this, the adverse effects of MC-LR on carrot plants and the potential bioaccumulation have not been previously investigated. Therefore, the aim of this study was to investigate whether a condition of exposure to MC-LR-contaminated water affects the plant phenotype and in particular the following parameters: (i) growth and photosynthesis; (ii) mineral and vitamin content in carrot roots; and (iii) toxin uptake and accumulation.

\section{Materials and methods}

\section{Biological material}

Microcystis aeruginosa (LEGE 91094) was grown as previously described by Pinheiro et al. (2013). Briefly, the cyanobacteria were grown to exponential phase under sterile conditions in $6 \mathrm{~L}$ glass containers with $4 \mathrm{~L}$ of $\mathrm{Z8}$ medium (Kótai, 1972), at $25{ }^{\circ} \mathrm{C}$, under $22 \mu \mathrm{Em}^{-2} \mathrm{~s}^{-1}$ light intensity, with a light/dark cycle of $14 / 10 \mathrm{~h}$. After 4 weeks of growth, the cultured cells were gathered by centrifugation $(20 \mathrm{~min}$, $4{ }^{\circ} \mathrm{C}, 4495 \mathrm{~g}$ ), frozen at $-80{ }^{\circ} \mathrm{C}$, and then freeze-dried (Pinheiro et al. 2013). The lyophilized material was stored at room temperature or $-20^{\circ} \mathrm{C}$ in the dark until M. aeruginosa extract preparation. In terms of toxins, this strain produces MC-LR (95\% of total MCs) and low amounts of MC-LA and [D-Asp3]-MC-LR (Vasconcelos, 1995). 
Carrot plants (Daucus carota) of the variety Soprano, with approximately 1 and 2 months old, were acquired in a greenhouse nursery. In the laboratory, plants were transferred to clear plastic containers $(350 \mathrm{~mL})$ with soil and grown in a semicontrolled environment, with natural light and temperature and controlled humidity. The soil used was Siro® Plant Universal Substrate and its main physicochemical properties were $\mathrm{pH}$ $\left(\mathrm{CaCl}_{2}\right)$, 5.5-6.5; humidity, 50-60\%; conductivity, 0.6$1.2 \mathrm{dS} / \mathrm{m} ; \mathrm{N}, 150-250 \mathrm{mg} / \mathrm{L} ; \mathrm{P}_{2} \mathrm{O}_{5}, 150-250 \mathrm{mg} / \mathrm{L} ; \mathrm{K}_{2} \mathrm{O}$, $300-500 \mathrm{mg} / \mathrm{L}$; organic material, $>70 \%$. After 1 week of acclimation, the plants were utilized for the exposure experiments.

\section{M. aeruginosa extracts and quantification of MC-LR}

M. aeruginosa extracts (MCE) were obtained from freeze-dried biomass (section 2.1). Cyanobacterial cells were suspended in distilled water $(0.2 \mathrm{~g}$ biomass $/ \mathrm{mL})$ and lysed by sonication in bath for $15 \mathrm{~min}$, followed by probe sonication on ice ( 5 cycles of $1 \mathrm{~min}$ at $60 \mathrm{HZ}$ ) (Vibracell VC50, Sonic and Materials, Newtown, USA). The homogenate was then subjected to ultracentrifugation $\left(60 \mathrm{~min}, 4^{\circ} \mathrm{C}\right.$ and $70,737 \mathrm{~g}$ ) and the supernatant was collected and stored at $-20^{\circ} \mathrm{C}$ prior to use. The concentration of MC-LR in the extracts was estimated by high performance liquid chromatography with a photo diode array detector (HPLC-PDA) according to Ramanan et al. (2000) with some modifications (Pereira et al., 2015) (the chromatogram of MCE with MC-LR is shown in online resource supplementary material-Figure $\mathrm{S} 1)$. The linear gradient elution consisted of (A) $\mathrm{MeOH}+0.1 \%$ TFA and (B) $\mathrm{H}_{2} \mathrm{O}+0.1 \%$ TFA (55\% A and $45 \% \mathrm{~B}$ at $0 \mathrm{~min}, 65 \% \mathrm{~A}$ and $35 \% \mathrm{~B}$ at $5 \mathrm{~min}, 80 \% \mathrm{~A}$ and $20 \% \mathrm{~B}$ at $10 \mathrm{~min}, 100 \% \mathrm{~A}$ at $15 \mathrm{~min}, 55 \% \mathrm{~A}$ and $45 \% \mathrm{~B}$ at 15.1 and $20 \mathrm{~min}$ ) with a flow rate of $0.9 \mathrm{~mL} / \mathrm{min}$. The injected volume was $20 \mu \mathrm{L}$, in duplicated. The DAD range was 210 $700 \mathrm{~nm}$, with a fixed wavelength at $238 \mathrm{~nm}$. The MC-LR was then separated on a Merck Lichrospher RP-1endcapped column ( $250 \mathrm{~mm}, 4.6 \mathrm{~mm}$ i.d., $5 \mu \mathrm{m}$ ) equipped with a guard column $(4 \times 4 \mathrm{~mm}, 5 \mu \mathrm{m})$, both maintained at $45^{\circ} \mathrm{C}$. Calculations were made using the external standard method (batch $\mathrm{n}^{\circ} 018 \mathrm{~K} 1209$, $10.025 \mu \mathrm{g} / \mathrm{mL}$ in $\mathrm{MeOH}, 98 \%$ purity, Cyano Biotech $\mathrm{GmbH}$, Berlin, Germany). The LOD and LOQ of this method are respectively $0.2 \mu \mathrm{g} \mathrm{MC}-\mathrm{LR} / \mathrm{mL}$ and $0.5 \mu \mathrm{g} \mathrm{MC}-\mathrm{LR} / \mathrm{mL}$.

\section{Exposure experiments}

Three independent exposure experiments were performed in this work. Each exposure experiment consisted in three groups comprehending the plants irrigated with non-contaminated water (control group, $0 \mu \mathrm{g} \mathrm{MC}-\mathrm{LR} / \mathrm{L}$ ), and plants irrigated with water contaminated with $M$. aeruginosa extract containing environmentally realistic toxin concentrations (treatment groups, 10 and $50 \mu \mathrm{g} \mathrm{MC}-\mathrm{LR} / \mathrm{L})$. For simplification, the water with diluted $M$. aeruginosa extracts will be referred to MC-LRcontaminated water throughout the work. Toxin concentration in the cyanobacterial extract was quantified each time before plant irrigation to certify that correct dilutions of MC-LR in the irrigation water (10 and $50 \mu \mathrm{g}$ MC-LR/L) were prepared.

Each experimental group was replicated three times, with six plants constituting each experimental replicate (1 experimental group $=3$ replicates $\times 6$ plants $=$ total of 18 plants $)$. Plants were irrigated twice a week with $40 \mathrm{~mL}$ of clean water or contaminated water. Soil moisture was routinely checked by using a moisture meter with four intensity levels (A to D, where A corresponds to dry soil and D to the high level of water content). If necessary clean water was added to maintain moisture in the soil, between levels B and C.

The experiment 1 lasted 28 days and aimed in the determination of fresh weight of carrots and leaves, photosynthetic capacity and quantification of MC-LR in carrot roots. The experiment 2 lasted 28 days and aimed in the quantification of minerals in carrots. The experiment 3 lasted 32 days and aimed in the quantification of vitamins in carrots (ascorbic acid and $\beta$-carotene).

In the experiments 1 and 2, the tissue sampling and measurements were carried out at the following time points: 0,14 , and 28 days after the onset of the experiment whereas in experiment 3 , the quantification of vitamins was carried out after 21 and 32 days of the onset of the experiment. At each time point, the roots and leaves were separated, weighted and plant tissues stored at $-80{ }^{\circ} \mathrm{C}$ for chemical and biochemical analyses.

\section{Physiological parameters: fresh weight and photosynthetic capacity}

Evaluation of plant growth was accomplished by determining fresh weight (FW) of leaves and roots. An average FW was estimated from a total of six plants per experimental replicate.

Photosynthetic capacity was determined through pulse amplitude modulation (PAM) fluorometry, with PAM 2000 (Walz, Effeltrich, Germany) at the start of the experiment and after 14 and 28 days of exposure to MC-LR-contaminated water. Eighteen plants of each experimental group $(n=18)$ were dark adapted for at least $30 \mathrm{~min}$ and leaves subsequently illuminated with a pulse of saturating light. The fluorescence emitted was immediately recorded by the instrument. This procedure allows measuring the maximum fluorescence yield of photosystem II (PSII) (Fv/Fm) that is directly related with the functional state of the PSII protein complex and the photosynthetic efficiency of the plants (Maxwell and Johnson, 2000).

\section{Mineral content of $D$. carota roots}

Root tissues of three $D$. carota plants were analyzed for their content of calcium $(\mathrm{Ca})$, magnesium $(\mathrm{Mg})$, potassium $(\mathrm{K})$, phosphorus $(\mathrm{P})$, sodium $(\mathrm{Na})$, manganese $(\mathrm{Mn})$, iron $(\mathrm{Fe})$, zinc $(\mathrm{Zn})$, copper $(\mathrm{Cu})$, and molybdenum (Mo). Before the 
analyses, all the roots were washed with deionized water to remove the soil and then a blade was used to assure that all soil debris had been removed. Only after this cleaning step the roots were frozen (at $-80{ }^{\circ} \mathrm{C}$ ) and then freeze-dried.

The digestion and analysis of carrot samples were performed according to Pinto et al. (2014). Briefly, freeze-dried roots of D. carota plants were digested in an MLS 1200 Mega high performance microwave digestion (Milestone, Sorisole, Italy) unit. About $0.2 \mathrm{~g}$ of powdered sample was weighed into PTFE vessels and $3 \mathrm{~mL}$ of $\mathrm{HNO}_{3}(\geq 69 \% \mathrm{w} / \mathrm{w}$, TraceSELECT®, Fluka, L'Isle d'Abeau Chesnes, France) and $1 \mathrm{~mL}$ of $30 \% \mathrm{H}_{2} \mathrm{O}_{2}(30 \% v / v$, TraceSELECT® Ultra, Fluka, Seelze, Germany) were added to each vessel. Subsequently, the mixture was submitted to the following microwave heating program (power/time): $250 \mathrm{~W} / 1 \mathrm{~min}, 0 \mathrm{~W} /$ $2 \mathrm{~min}, 250 \mathrm{~W} / 5 \mathrm{~min}, 400 \mathrm{~W} / 5 \mathrm{~min}$, and $600 \mathrm{~W} / 5 \mathrm{~min}$. Sample solutions were then analyzed by a 3100 flame atomic absorption spectroscopy (AAS) instrument (Perkin Elmer, Überlingen, Germany) and by inductively coupled plasmamass spectrometry (ICP-MS, iCAPTM Q, Thermo Fisher Scientific, Bremen, Germany) for total metal content. For AAS analysis, multi-element calibration standards were prepared from $1000 \mathrm{mg} / \mathrm{L}$ single-element standard solutions of $\mathrm{Ca}, \mathrm{Mg}, \mathrm{K}$, and Na (Sigma-Aldrich, St. Louis, MO, USA). For ICP-MS analysis, calibration standards were prepared from the $10 \mu \mathrm{g} / \mathrm{mL}$ multi-element ICP-MS standard solution (PlasmaCAL SCP-33-MS, SCP Science, Baie-d'Urfé, Quebec, Canada). All solutions were prepared using ultrapure water $\left(\geq 18.2 \mathrm{M} \Omega \mathrm{cm}\right.$ at $25^{\circ} \mathrm{C}$ ) obtained with a Sartorius Arium ${ }^{\circledR}$ pro water purification system (Goettingen, Germany). Phosphorus was determined according to Murphy and Riley (1962). The certified reference material BCR 679 (white cabbage, supplied by EC Institute for Reference Materials and Measurements, Geel, Belgium) was used to check the accuracy and precision of the analytical procedures. Results were expressed on a DW basis.

\section{Ascorbic acid content of $D$. carota roots}

Ascorbic acid extraction was performed according to Ismail \& Sook Fun (2003) with slight modifications. Roots (10 g) were homogenized, on ice bath, with a hand blender in $20 \mathrm{~mL}$ of an extracting solution containing meta-phosphoric acid $(0.3 \mathrm{M})$ and acetic acid $(1.4 \mathrm{M})$. The mixture was placed in centrifuge tubes $(50 \mathrm{~mL}$ ) (wrapped with aluminum foil) and mixed at $100 \mathrm{rpm}$ with the aid of an orbital shaker for $15 \mathrm{~min}$ at room temperature. Samples were immediately centrifuged (20 min, $4{ }^{\circ} \mathrm{C}, 4495 \mathrm{~g}$ ) and the supernatant collected and stored at $-20{ }^{\circ} \mathrm{C}$ for later quantification by HPLC-PDA.

The ascorbic acid detection and quantification was also performed following the protocol described by Ismail \& Sook Fun (2003). The separation was performed with $1 \% \mathrm{MeOH}$ in isocratic mode with a flow rate of $0.8 \mathrm{~mL} / \mathrm{min}$. The injected volume was $20 \mu \mathrm{L}$, in duplicated. The PDA range was 210 $400 \mathrm{~nm}$, with a fixed wavelength at $250 \mathrm{~nm}$. The chromatography system and separation column used were those described above (section 2.2.), but the column temperature used was $25^{\circ} \mathrm{C}$. Calculations were made using the external standard method (batch $n^{\circ}$ LC01471V, Supelco, Bellefonte, PA, USA).

\section{$\beta$-Carotene content of $\boldsymbol{D}$. carota roots}

$\beta$-Carotene extraction was performed according to Ahamad et al. (2007) with some modifications. Roots (10 g) were homogenized in $70 \mathrm{~mL}$ of acetone with $0.1 \%$ BHT with the help of a hand blander. The resulting extract was filtered through Buchnar's funnel. The residue was washed twice with $40 \mathrm{~mL}$ of acetone and then discarded. The filtrate was combined with $20 \mathrm{~g}$ of anhydrous sodium sulfate. The anhydrous sodium sulfate was removed through filtration and the volume of extract was reduced by rotatory evaporator. The extract was transferred quantitatively to $100 \mathrm{~mL}$ volumetric flask and the volume was made with $80 \%$ acetone with $0.1 \%$ BHT.

$\beta$-Carotene detection and quantification was achieved by HPLC-PDA following the protocols described by Ismail \& Sook Fun (2003) and Ahamad et al. (2007) with some modifications. The linear gradient elution consisted of (A) $\mathrm{MeOH}$ $+0.1 \%$ TFA $(v / v)$ and (B) Hexane $+0.1 \%$ TFA $(\mathrm{v} / v)(85 \%$ A and $15 \% \mathrm{~B}$ at $0 \mathrm{~min}, 85 \% \mathrm{~A}$ and $15 \% \mathrm{~B}$ at $5 \mathrm{~min}, 70 \% \mathrm{~A}$ and $30 \% \mathrm{~B}$ at $15 \mathrm{~min}, 85 \% \mathrm{~A}$ and $15 \% \mathrm{~B}$ at 16 and $20 \mathrm{~min}$ ), with a flow rate of $0.8 \mathrm{~mL} / \mathrm{min}$. The injected volume was $20 \mu \mathrm{L}$, in duplicated. The PDA range was $210-400 \mathrm{~nm}$, with a fixed wavelength at $450 \mathrm{~nm}$. The chromatography system and separation column used were those described above (section 2.2.), but the column temperature was changed to $30^{\circ} \mathrm{C}$. Calculations were made using the external standard method (batch n ${ }^{\circ}$ SLBB9126V, Sigma-Aldrich, St. Louis, MO, USA).

\section{MC-LR extraction for quantification in carrots and soil}

MC-LR was extracted from carrot roots exposed to 0,10 , and $50 \mu \mathrm{g} \mathrm{MC-LR/L} \mathrm{for} 14$ and 28 days, and from soil exposed to $50 \mu \mathrm{g} \mathrm{MC}-\mathrm{LR} / \mathrm{L}$ for 28 days to $50 \mu \mathrm{g} \mathrm{MC}-\mathrm{LR} / \mathrm{L}$. For the purpose of food safety assessment only the edible part of the plant (carrots) was analyzed regarding toxin accumulation.

Carrot samples and soil were homogenized in $80 \%(\mathrm{v} / \mathrm{v})$ $\mathrm{MeOH}+0.1 \%(v / v)$ TFA ( $1 \mathrm{~g}$ biomass $/ 5 \mathrm{~mL}$ solvent $)$ with the aid of a hand blender. The homogenate was allowed to stand for a period of about $60 \mathrm{~min}$ to increase the recovery of toxin from the tissues or soil. Subsequently, the material was sonicated with a probe (Vibracell) for $5 \mathrm{~min}$ at $60 \mathrm{HZ}$, on ice, and then centrifuged $\left(20 \mathrm{~min}, 4^{\circ} \mathrm{C}, 4495 \mathrm{~g}\right)$. The supernatants were collected and aliquots of 1 or $10 \mathrm{~mL}$, depending on the matrix and expected concentration of the toxin, were evaporated in a vacuum concentrator (Acid-resistant Centrivap Concentrator, Labconco, Kansas City, MO, USA). The residues were 
subsequently re-suspended in $1 \mathrm{~mL} \mathrm{H}_{2} \mathrm{O}$ or in $0.5 \mu \mathrm{L}$ of $\mathrm{MeOH} 80 \%$, depending on the method used for further toxin quantification. Two methods having lower LODs in comparison to HPLC, the ELISA and LC-MS/MS, were employed to quantify the low toxin in soil and carrot matrices.

\section{Quantification of MC-LR by ELISA immunoassay test}

Carrot and soil aqueous extracts were quantified using the ELISA kit specific for detection and quantification of microcystins and nodularins (Microcystins ADDA-ELISA Microtiter Plate Abraxis $\AA$, Warminster, PA, USA) with $\mathrm{LOD}=0.1 \mu \mathrm{g} \mathrm{MC} \mathrm{Eq./L}$ and $\mathrm{LOQ}=0.15 \mu \mathrm{g} \mathrm{MC}$ Eq./L.

All samples were applied in duplicate to the wells provided in the kit and the procedure was performed according to the manufacturer's instructions. The Abs at $450 \mathrm{~nm}$ was determined on a plate reader (Biotek Synergy) equipped with 1.06 Gen 5 software. Based on the results obtained for the positive control, a calibration curve was established with the values of Abs of the standard solutions $(0.0,0.15,0.40,1.0$, 2.0 , and $5.0 \mu \mathrm{g} / \mathrm{L})$ present in the kit, and then the concentration of MC equivalents (g MC Eq./L) was determined in each sample. Values lower than $0.10 \mu \mathrm{g} / \mathrm{L}$ were considered below the LOD and the matrix effects were corrected by subtracting the value of control samples to those exposed to the toxin.

\section{Quantification of MC-LR by LC-ESI-MS/MS}

MC-LR in carrots and soil extracts (MeOH $80 \%)$ was quantified by injection in a Liquid Phase Chromatograph Finnigan Surveyor (Thermo Scientific, San Jose, CA, USA), coupled with a spectrometry detector (MS Mass LCQ FleetTM ion trap), with electrospray (ESI) interface, including a Surveyor LC pump, a Surveyor auto sampler and a Surveyor photoelectric PDA detector. The program used for data acquisition and processing was XcaliburTM version 2 (Thermo Scientific, San Jose, CA, USA). The mass spectrometer was operated in a multiple reaction monitoring mode (MRM) with collision energy of $35 \mathrm{eV}$. The capillary voltage and tube lens were maintained at 22 and $120 \mathrm{kV}$, respectively; the spray voltage was $5.5 \mathrm{kV}$. Nitrogen was used as a sheath and auxiliary gas. The sheath gas flow rate was set at 80 (arbitrary units) and the auxiliary gas at 20 . The capillary temperature was held at $350^{\circ} \mathrm{C}$. Helium was used as a collision gas in the ion trap at a pressure of 3 bar.

Separation was achieved on $\mathrm{C}_{18}$ Hypersil Gold column $(100 \times 4.6 \mathrm{~mm}$ I.D., $5 \mu \mathrm{m}$, ThermoScientific, Waltham, MA, USA) kept at $25^{\circ} \mathrm{C}$, with a flow rate of $0.8 \mathrm{~mL} / \mathrm{min}$ in the case of carrots sample and $0.7 \mathrm{~mL} / \mathrm{min}$ in the case of soil samples. The injected volume was $20 \mu \mathrm{L}$ in loop partial mode. Samples were injected in positive polarity mode, in Full scan $(270-1500 \mathrm{~m} / \mathrm{z})$. The standards and samples were injected in duplicate and at each set of 10 samples was introduced a blank and two standards with different concentration. The standard solution of MC-LR was purchased from DHI LAB Products (Hørsholm, Denmark, Batch $n^{\circ}$ MCLR-110), with a concentration of $11.026 \mu \mathrm{g} / \mathrm{mL}$. In the case of carrot samples, the system was calibrated using six dilutions of the standard solution of MC-LR (between 0.55 and $11.1 \mu \mathrm{g} / \mathrm{mL}$ ) diluted in $50 \% \mathrm{MeOH}$. In the case of soil samples, the system was calibrated using the seven standard MC-LR dilutions $(0.0085$ to $1.8 \mu \mathrm{g} / \mathrm{mL})$ in $50 \% \mathrm{ACN}$.

To separate the MC-LR present in D. carota roots, a gradient elution was used with mobile phase A methanol and $\mathrm{B}$ water, both acidified with $0.1 \%$ formic acid $(55 \% \mathrm{~A}$ and $45 \% \mathrm{~B}$ at $0 \mathrm{~min}, 90 \% \mathrm{~A}$ and $10 \% \mathrm{~B}$ at $12 \mathrm{~min}, 100 \% \mathrm{~A}$ at $12.5 \mathrm{~min}$, $100 \% \mathrm{~A}$ at $15 \mathrm{~min}, 45 \% \mathrm{~A}$ and $55 \% \mathrm{~B}$ at 15.01 and $25 \mathrm{~min}$ ). Under these conditions, the MC-LR retention time was $6.07 \mathrm{~min}$ and the LOD was $6.48 \mu \mathrm{g} / \mathrm{L}$. To quantify the MC-LR present in soil, a gradient elution was also used with mobile phase A acetonitrile and $\mathrm{B}$ water, both acidified with $0.1 \%$ formic acid $(30 \%$ $\mathrm{A}$ and $70 \% \mathrm{~B}$ at 0 min and $5 \mathrm{~min}, 99 \% \mathrm{~A}$ and $1 \% \mathrm{~B}$ at $22 \mathrm{~min}$ and $25 \mathrm{~min}, 70 \% \mathrm{~A}$ and $30 \% \mathrm{~B}$ at $26 \mathrm{~min}$ and $35 \mathrm{~min}$ ). Under these conditions, the MC-LR retention time was $10.77 \mathrm{~min}$. The LOD and LOQ were, respectively, 5.7 and $8.5 \mu \mathrm{g} / \mathrm{L}$.

Samples were analyzed using the mass-to-charge ratio $(m / z)$ transition of $995>599$, at $35 \mathrm{eV}$ collision energy. The MC-LR transition was monitored for 1 microscan time. The precursor ion $(\mathrm{m} / \mathrm{z}$ 995) and MC-LR reference fragment ions with $\mathrm{m} / \mathrm{z}$ values of $375,553,599,866$, and 977 were monitored in the MS/MS mode, in order to validate the presence of the toxin in the roots and soil.

\section{Statistical analysis}

All measurements were performed in triplicate $(n=3)$, unless otherwise stated. The normality and homogeneity of variance was checked with respectively the Shapiro-Wilk and Levene tests. Confirmed these assumptions data were analyzed by one-way analysis of variance (ANOVA) followed by Tukey's post hoc test. When one of these assumptions was not followed, data were transformed before one-way analysis of variance (ANOVA) and Tukey's post hoc test. When, even after the data transformation, the assumptions were not verified, the non-parametric Kruskal-Wallis and Mann-Whitney $U$ tests with Dunn-Bonferroni correction were used. The significance level was set at $p<0.05$. All statistical analysis was performed in the IBM SPSS Statistics program (version 22).

\section{Results and discussion}

\section{Effects of MC-LR extracts on carrot plants growth and photosynthetic capacity}

Overall, upon visual inspection, the treatments applied in this study did not produce perceptible deleterious effects in carrot 
plants (e.g., chlorosis or necrosis). The effects of MC-LR on carrot growth were studied by comparing the mean FW in the control and treated plants (Fig. 1). Exposure of carrot plants to water containing $50 \mu \mathrm{g}$ MC-LR/L for 28 days decreased significantly the FW of roots $(p<0.05)$ (Fig. 1).

The alteration of root FW could be interpreted as a first signal of stress induced by MC-LR-contaminated water. This interpretation raises the hypothesis that more severe toxic effects can emerge from the prolonged (chronic) exposure to low toxin concentrations. Growth inhibition of plants due to MC-LR exposure has been reported by several studies (McElhiney et al., 2001, Chen et al., 2004, Pflugmacher et al., 2006, Pflugmacher et al., 2007b, Saqrane et al., 2008, Pereira et al., 2009, Chen et al., 2012, El Khalloufi et al., 2012, Lahrouni et al., 2013). The growth and development of Brassica napus, Malus pumila, and Oriza sativa seedlings were inhibited after exposure to a crude extract containing $3000 \mu \mathrm{g}$ MC-LR/L during 4 days (B. napus and $O$. sativa) and 14 days (M. pumila) (Chen et al., 2004, Chen et al., 2010). Lycopersicum esculentum growth inhibition was also reported by El Khalloufi et al. (2012) in a 30-day exposure to M. aeruginosa extract containing 2220-22,240 $\mu \mathrm{g}$ MC-LR/ L. The present study differs from the above studies in that 28 days of exposure to $50 \mu \mathrm{g} / \mathrm{L}$ MC-LR were needed to observe a decrease in the growth of carrot roots, denoting the low toxicity associated to the experiments. This is in accordance with what has been reported from experiments with low toxin concentrations and soil-grown crops, where in general the effects on plant growth are less pronounced (Corbel et al., 2015). The increase of FW of lettuce leaves after exposure to low concentrations ( 1 and $10 \mu \mathrm{g} / \mathrm{L}$ ) of MC-LR was reported by Freitas et al. (2015). In contrast, the highest concentration of MC-LR $(100 \mu \mathrm{g} / \mathrm{L})$ produced a significant decrease in FW of lettuce leaves. Other studies reported absence of growth inhibition in $O$. sativa exposed to cyanobacterial extract containing between 0.3 and $78 \mu \mathrm{g}$ MC-LR/L (Prieto et al. 2011, Azevedo et al., 2014). Thus, the dissimilarities observed in FW in several of the above mentioned studies highlight the need of more research, particularly on low, environmentally relevant toxin concentrations, to clarify the extent of the impact of cyanotoxins in agriculture.

Regarding the photosynthetic capacity, a statistically significant increase in $\mathrm{Fv} / \mathrm{Fm}$ in plants irrigated with 10 and $50 \mu \mathrm{g}$ MC-LR/L was verified in comparison to the control plants (Fig. 2). The ideal value of $\mathrm{Fv} / \mathrm{Fm}$ for most plant species is around 0.83 (Maxwell and Johnson, 2000). Values significantly lower than this may indicate that the plant is under physiological stress (Maxwell and Johnson, 2000). Since this condition was not verified in this study, we can conclude that MC-LR at 10 and $50 \mu \mathrm{g} / \mathrm{L}$ do not impair photosynthesis in D. carota. These results agree with the absence of significant growth effects in leaves and with the reduced inhibition of root growth at the highest toxin concentration. Nevertheless, Fv/Fm values above 0.83 are unusual and poorly understood at the physiological and plant performance levels. Increase in Fv/Fm could indicate improved photosynthetic capacity and connected to this, a possible raise in the physiological performance of the plant and its capacity to respond to stress. Li et al. (2014) observed that elevated $\mathrm{CO}_{2}$ alleviates metal toxicity in Sedum alfredii plants and alongside increases $\mathrm{Fv} / \mathrm{Fm}$, suggesting that photosynthetic capacity is improved by $\mathrm{CO}_{2}$ and this may contribute to the tolerance to metals. Moreover, persistent stimulation of photosynthesis in mulberry plants under elevated $\mathrm{CO}_{2}$ showed to facilitate photosynthetic acclimation in this plant, due perhaps to efficient sink capacity (Li et al., 2014).

These results can also be interpreted in light of the hormesis concept. According to this concept, low concentrations of a drug or toxicant can lead to a stimulation of the metabolism of the exposed organism and its defenses to the toxicant. The
Fig. 1 Fresh weight of carrot plants (roots and leaves) after being exposed during 14 and 28 days to MC-LR. Control: light gray bars; $10 \mu \mathrm{g} / \mathrm{L}$ MC-LR: dark gray bars; $50 \mu \mathrm{g} / \mathrm{L}$ MC-LR: black bars. Values are expressed as mean $\pm \operatorname{SD}(n=3)$. Statistical analyses: ANOVA followed by Tukey's post hoc test. Different letters ( $a$ and $b$ ) mean significant differences $(p<0.05)$

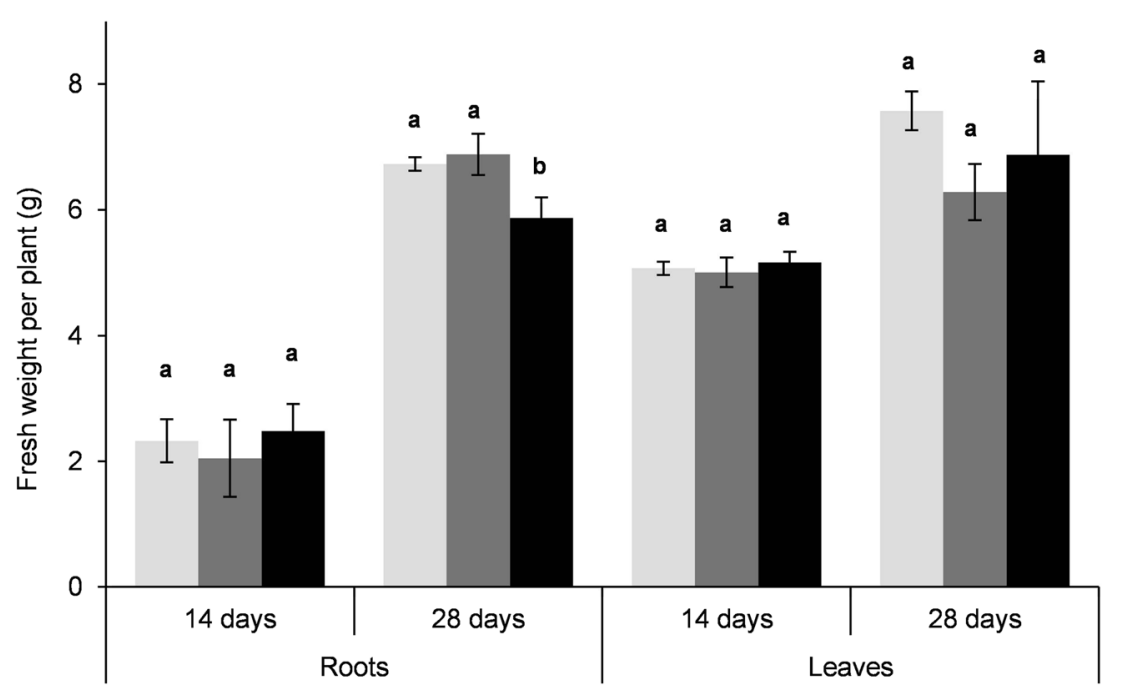




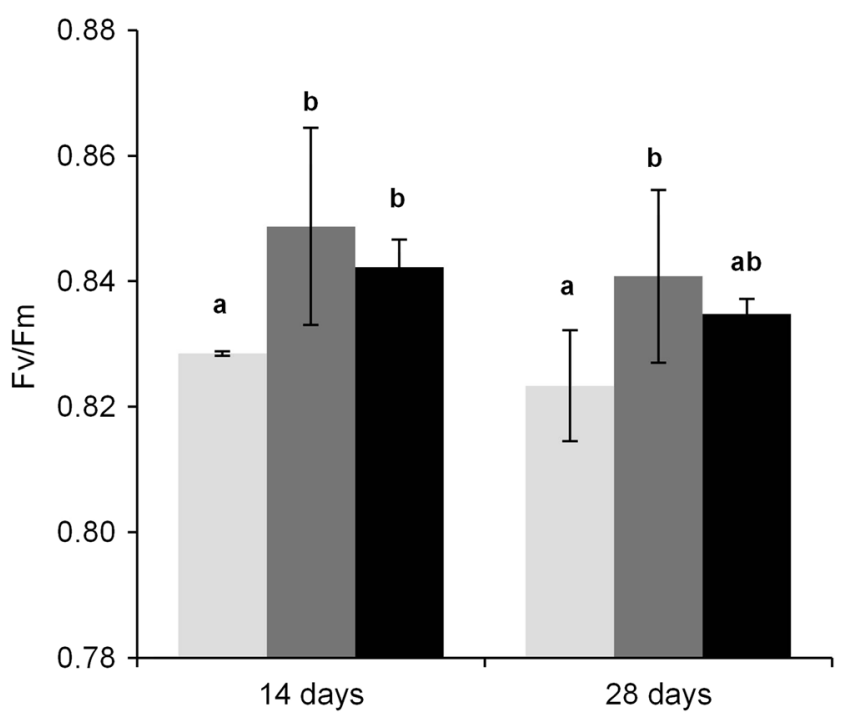

Fig. 2 Maximum fluorescence values $(\mathrm{Fv} / \mathrm{Fm})$ after plants being exposed during 14 and 28 days to MC-LR. Control: light gray bars; $10 \mu \mathrm{g} / \mathrm{L}$ MC-LR: dark gray bars; $50 \mu \mathrm{g} / \mathrm{L}$ MC-LR: black bars. Values are expressed as mean $\pm \operatorname{SD}(n=18)$. Statistical analyses: Kruskal-Wallis and Mann-Whitney $U$ tests with Dunn-Bonferroni correction. Different letters mean significant differences $(p<0.05)$

increase of some physiological parameters in plants exposed to low concentrations of MC-LR was previously interpreted by Bibo et al., (2008) according to this concept.

In agreement with the present results also BittencourtOliveira et al. (2016) reported recently an increase in the net photosynthetic rate in lettuce plants exposed to $M$. aeruginosa toxic extracts ( 0.65 to $13 \mu \mathrm{g} / \mathrm{L}$ total MCs). Also of interest was the absence of morphological effects in plants (i.e., root, shoot, and leaf weights). The increase in the net photosynthetic rate was advanced by the authors as a mechanism of lettuce plants to synthesize additional substrates to supply energy and to be utilized in the biosynthesis of important antioxidant molecules and enzymes that protect from oxidative stress induced by MCs.

To note that the contaminated water utilized in this study was prepared from the dilution of a toxic Microcystis extract, therefore other potential cyanobacterial bioactive metabolites could be present in the water along with the main toxin MCLR. Therefore, the biological activity of the water may not be confined to MC-LR but also reflect the interaction of other non-identified metabolites from the water with MC-LR and with the plant. However, for simplification and because only MC-LR was quantified in the water as the main bioactive compound, the results are reported only to this toxin. It should be noted as well that in terms of chemical composition and bioactivity diluted crude extracts may resemble environmental waters affected by toxic blooms thereby have been useful in environmental risk assessment of contaminated water bodies. Cyanobacterial crude extracts are known to induce pronounced detrimental biological effects even when lacking MCs (Sadler and von Elert, 2014). Comparatively crude cyanobacterial extracts are generally more bioactive than enriched MC fractions (Burýsková et al., 2006). Metabolomic analyses enabled to identify several types of bioactive metabolites from cyanobacterial extracts (Bláhová et al., 2013; Sadler and von Elert, 2014). Among these are compounds like lipopolysaccharides, cyanopeptolins (CPs), and the cyclamides, widely distributed among cyanobacteria, and which have shown significant biological activities to different organisms (Bláhová et al., 2013; Sadler and von Elert, 2014).

\section{Effects of MC-LR extracts on mineral content of carrot roots}

According to our knowledge, this is the first study where the micro mineral content of roots was measured in the context of cyanotoxin contamination. Overall, the exposure to MC-LRcontaminated water (10 and $50 \mu \mathrm{g} \mathrm{MC}-\mathrm{LR} / \mathrm{L}$ ) resulted in significant changes in macro and micro minerals of carrot roots (Mg, Na, K, Fe, Zn, Mo, and P) (Table 1). The mineral content was affected especially after 28 days of exposure to the highest MC-LR concentration (50 $\mu \mathrm{g}$ MC-LR/L), where a general increase was observed in relation to the control group (Table 1). However, Ca was not affected by the contaminated water in any exposure condition, and Mo and $\mathrm{P}$, decreased in concentration. We also observed differences between treatments with regard to mineral accumulation and a tendency for the decrease of Fv/Fm with the exposure to the highest toxin concentration.

In general, the results obtained in our study are in agreement with those reported by Saqrane et al. (2009), El Khalloufi et al. (2012) and Lahrouni et al. (2013). The macro mineral content $\left(\mathrm{Na}^{+}, \mathrm{K}^{+}, \mathrm{Ca}^{2+}, \mathrm{P}\right.$, and $\left.\mathrm{N}\right)$ in roots of Triticum durum, Zea mays, Pisum sativum, Lens esculenta (Saqrane et al., 2009), and Lycopersicon esculentum was shown to increase in a concentration-dependent manner after exposing the plants to MC-LR (Saqrane et al., 2009; El Khalloufi et al., 2012). Moreover, Saqrane et al. (2009) suggested that the increase in mineral content vary according to plant species. Deleterious effects were observed in tomato plants when exposed to MC-LR concentrations between 1120 and $2240 \mu \mathrm{g} / \mathrm{L}$ (El Khalloufi et al., 2012).

In this study, carrots accumulated minerals in a higher concentration as compared with control carrots. Therefore, it can be suggested that irrigation with MC-LR-contaminated water alter the chemical composition of this edible part of the plant, and consequently its nutritional value. Lahrouni et al. (2013) proposed that variations in the concentration of minerals might result from loss of plant membrane permeability caused by MC-LR. In addition to the possible action of MC-LR in the assimilation of minerals, it should be taken into consideration also the effect of any soil enrichment in minerals derived from irrigation and the use of diluted Microcytis extract. 
Table 1 Effects of 10 and $50 \mu \mathrm{g}$ MC-LR/L in the concentration of the macro and micro minerals in carrots of plants exposed during 14 and 28 days to the toxin. Values are expressed as mean $\pm \operatorname{SD}(n=3)$.
Statistical analyses: ANOVA followed by Tukey's post hoc test. Increase $(\uparrow)$, decrease $(\downarrow)(p<0.05)$, or no significant statistical effect on mineral concentration (-) in relation to the control group of plants

\begin{tabular}{|c|c|c|c|c|c|c|}
\hline & \multicolumn{3}{|l|}{14 days } & \multicolumn{3}{|l|}{28 days } \\
\hline & Control & $10 \mu \mathrm{g} \mathrm{MC}-\mathrm{LR} / \mathrm{L}$ & $50 \mu \mathrm{g}$ MC-LR/L & Control & $10 \mu \mathrm{g}$ MC-LR/L & $50 \mu \mathrm{g}$ MC-LR/L \\
\hline Iron $(\mathrm{Fe})$ & $2.29 \pm 1.08$ & $\begin{array}{l}4.73 \pm 1.07 \\
(-)\end{array}$ & $\begin{array}{l}6.02 \pm 1.88 \\
(\uparrow)\end{array}$ & $20.66 \pm 0.70$ & $\begin{array}{l}24.78 \pm 2.06 \\
(\uparrow)\end{array}$ & $\begin{array}{l}38.09 \pm 2.63 \\
(\uparrow)\end{array}$ \\
\hline $\begin{array}{l}\text { Manganese } \\
(\mathrm{Mn})\end{array}$ & $24.22 \pm 3.15$ & $\begin{array}{l}35.32 \pm 5.37 \\
(\uparrow)\end{array}$ & $\begin{array}{l}34.55 \pm 1.24 \\
(\uparrow)\end{array}$ & $43.31 \pm 6.79$ & $\begin{array}{l}54.58 \pm 2.10 \\
(\uparrow)\end{array}$ & $\begin{array}{l}58.38 \pm 4.54 \\
(\uparrow)\end{array}$ \\
\hline $\begin{array}{l}\text { Copper } \\
(\mathrm{Cu})\end{array}$ & $2.63 \pm 0.32$ & $\begin{array}{l}1.89 \pm 0.11 \\
(\downarrow)\end{array}$ & $\begin{array}{l}1.78 \pm 0.23 \\
(\downarrow)\end{array}$ & $4.62 \pm 0.33$ & $\begin{array}{l}5.80 \pm 0.09 \\
(\uparrow)\end{array}$ & $\begin{array}{l}7.12 \pm 0.14 \\
(\uparrow)\end{array}$ \\
\hline Zinc (Zn) & $18.29 \pm 1.97$ & $\begin{array}{l}12.44 \pm 0.79 \\
(-)\end{array}$ & $\begin{array}{l}27.74 \pm 1.47 \\
(\uparrow)\end{array}$ & $28.08 \pm 3.19$ & $\begin{array}{l}15.24 \pm 2.05 \\
(-)\end{array}$ & $\begin{array}{l}34.90 \pm 1.56 \\
(\uparrow)\end{array}$ \\
\hline $\begin{array}{l}\text { Molybdenum } \\
\text { (Mo) }\end{array}$ & $260.88 \pm 27.51$ & $\begin{array}{l}96.06 \pm 20.57 \\
(\downarrow)\end{array}$ & $\begin{array}{l}136.31 \pm 40.87 \\
(\downarrow)\end{array}$ & $220.24 \pm 35.55$ & $\begin{array}{l}88.70 \pm 6.77 \\
(\downarrow)\end{array}$ & $\begin{array}{l}175.96 \pm 41.64 \\
(\downarrow)\end{array}$ \\
\hline $\begin{array}{l}\text { Phosphorus } \\
(\mathrm{Ph})\end{array}$ & $1672.82 \pm 28.61$ & $\begin{array}{l}2048.57 \pm 96.03 \\
(\uparrow)\end{array}$ & $\begin{array}{l}1887.93 \pm 45.52 \\
(\uparrow)\end{array}$ & $2678.49 \pm 155.14$ & $\begin{array}{l}2647.40 \pm 71.21 \\
(-)\end{array}$ & $\begin{array}{l}2520.75 \pm 173.63 \\
(\downarrow)\end{array}$ \\
\hline $\begin{array}{l}\text { Magnesium } \\
(\mathrm{Mg})\end{array}$ & $1498.38 \pm 152.71$ & $\begin{array}{l}1533.91 \pm 65.16 \\
(\uparrow)\end{array}$ & $\begin{array}{l}1537.54 \pm 47.55 \\
(-)\end{array}$ & $1712.49 \pm 71.84$ & $\begin{array}{l}1578.38 \pm 106.66 \\
(\downarrow)\end{array}$ & $\begin{array}{l}1831.84 \pm 74.33 \\
(\uparrow)\end{array}$ \\
\hline $\begin{array}{l}\text { Sodium } \\
\text { (Na) }\end{array}$ & $7114.07 \pm 38.05$ & $\begin{array}{l}5901.97 \pm 590.96 \\
(\downarrow)\end{array}$ & $\begin{array}{l}5402.85 \pm 55.56 \\
(\downarrow)\end{array}$ & $6764.24 \pm 469.54$ & $\begin{array}{l}7475.41 \pm 261.86 \\
(-)\end{array}$ & $\begin{array}{l}8671.16 \pm 55.44 \\
(\uparrow)\end{array}$ \\
\hline $\begin{array}{l}\text { Calcium } \\
(\mathrm{Ca})\end{array}$ & $2603.91 \pm 157.40$ & $\begin{array}{l}2971.58 \pm 133.24 \\
(-)\end{array}$ & $\begin{array}{l}2677.09 \pm 227.75 \\
(-)\end{array}$ & $3060.74 \pm 102.73$ & $\begin{array}{l}3130.52 \pm 104.62 \\
(-)\end{array}$ & $\begin{array}{l}3083.00 \pm 107.49 \\
(-)\end{array}$ \\
\hline $\begin{array}{l}\text { Potassium } \\
(\mathrm{K})\end{array}$ & $21.20 \pm 1.31$ & $\begin{array}{l}22.84 \pm 1.53 \\
(-)\end{array}$ & $\begin{array}{l}19.66 \pm 1.35 \\
(-)\end{array}$ & $21.26 \pm 0.67$ & $\begin{array}{l}24.42 \pm 0.97 \\
(\uparrow)\end{array}$ & $\begin{array}{l}29.84 \pm 1.68 \\
(\uparrow)\end{array}$ \\
\hline
\end{tabular}

Minerals are essential to ensure plants' life cycle and it is possible that some general functions in plant metabolism could be affected due to the disturbance of mineral uptake and translocation promoted by MC-LR. For example, it is well known that the mineral content of the plants can significantly affect photosynthesis, since they participate in several functions, having a direct and/or indirect role in this process. In this study, all minerals recognized as essential to photosynthesis ( $\mathrm{K}, \mathrm{Mg}, \mathrm{Fe}, \mathrm{Mn}, \mathrm{Cu}, \mathrm{Zn}$ ) increased in roots of plants exposed to MC-LR-contaminated water; thus, it can be hypothesized that the increase in mineral content contributed to the observed increase in $\mathrm{Fv} / \mathrm{Fm}$.

The ability of crop plants to cope with abiotic stress and to maximize nutritional quality is furthermore of major relevance for food security. In spite of the apparent benefits of the increase of mineral content with the exposure to MC-LRcontaminated water, there are attendant risks (e.g., toxin contamination) and unexpected consequences that can threaten food safety and that should be further studied.

\section{Effects of MC-LR extracts on ascorbic acid and $\beta$-carotene content of carrot roots}

The exposure of carrot plants to contaminated water containing 10 and $50 \mu \mathrm{g} \mathrm{MC}-\mathrm{LR} / \mathrm{L}$ significantly decreased the content of ascorbic acid in carrots (Fig. 3), but did not affect the $\beta$-carotene content (Fig. 4).

In plants, ascorbic acid is known as the largest primary antioxidant. It acts as primary substrate in the enzymatic pathway of ROS detoxification, such as $\mathrm{H}_{2} \mathrm{O}_{2}$ and directly in the neutralization of superoxide radical $\left(\mathrm{O}_{2}{ }^{-}\right)$, oxygen singlets $\left(\mathrm{O}^{-}\right)$, and hydroxyl radicals $\left(\mathrm{OH}^{-}\right)$. It is also a powerful secondary antioxidant, reducing the oxidized form of $\alpha$-tocopherol (Noctor and Foyer, 1998). Furthermore, the ascorbic acid has been identified as of major importance in the regulation of senescence, in defense against pests and in plant growth (Mazid et al., 2011).

It was reported that ROS produced by various types of stress lead to a decrease in the ascorbic acid by its oxidation and formation of dehydroascorbic acid (oxidized form) (Fridovich and Handler, 1961). Keutgen and Pawelec (2007), after studying the effect of abiotic stress $(\mathrm{NaCl})$ in Fragaria, hypothesized that a decrease of ascorbic acid occurs when the oxidation rate exceeds the capacity of recycling. Thus, it can be hypothesized that the oxidation of ascorbic acid, due to the induction of oxidative stress promoted by MC-LR could be the possible cause of the decrease of this compound in carrots. The content of other non-enzymatic antioxidants, such as phenolic compounds and $\alpha$ - and $\beta$-tocopherol, has been reported to change in plants after their exposure to MC-LR (El Khalloufi et al., 2012; Lahrouni et al., 2013; Stüven and Pflugmacher, 2007). According to these results, 


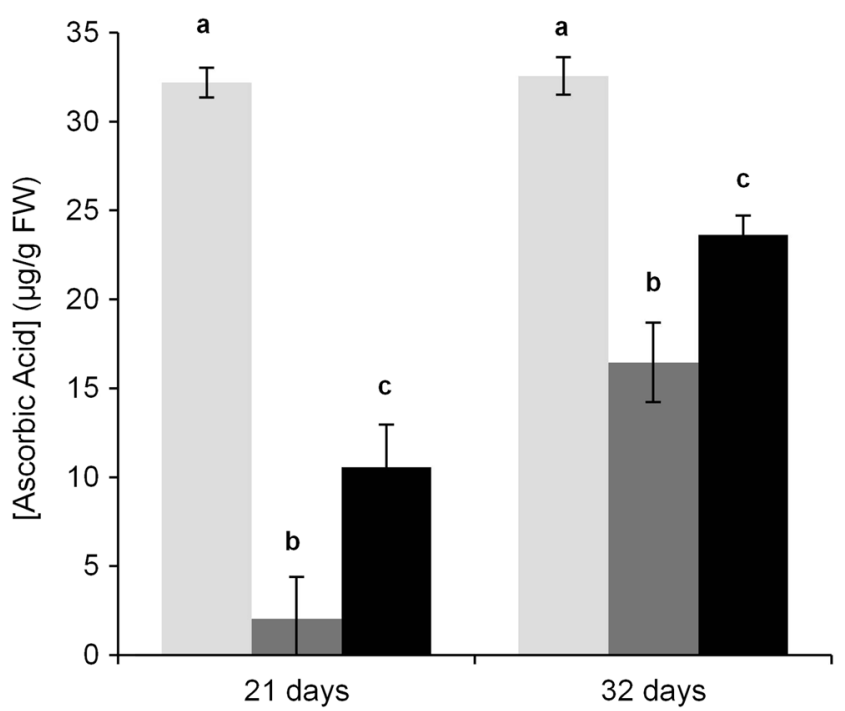

Fig. 3 Ascorbic acid content in carrots from plants exposed during 21 and 32 days to MC-LR. Control: light gray bars; $10 \mu \mathrm{g} / \mathrm{L}$ : dark gray bars; $50 \mu \mathrm{g} / \mathrm{L}$ : black bars. Values are expressed as mean $\pm \mathrm{SD}(n=3)$. Statistical analyses: ANOVA followed by Tukey's post hoc test. Different letters mean significant differences $(p<0.05)$

ascorbic acid, but not $\beta$-carotene, content in carrot roots can be seen as a marker of the presence and activity of MC-LR. The results obtained thus raise concerns to the detrimental effects of MC-LR-contaminated water on the nutritional value of carrots.

\section{Accumulation of MC-LR in carrot roots}

ELISA test and LC-ESI-MS/MS were employed to quantify the amount of MC-LR in carrots after the exposure to

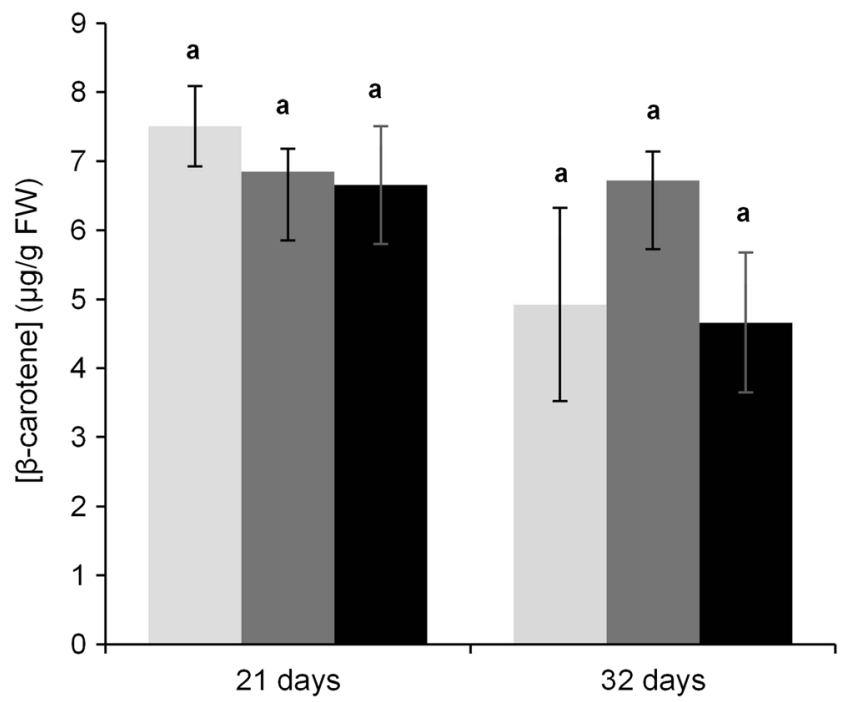

Fig. $4 \beta$-Carotene content in carrots from plants exposed during 21 and 32 days to MC-LR. Control: light gray bars; $10 \mu \mathrm{g} / \mathrm{L}$ : dark gray bars; $50 \mu \mathrm{g} / \mathrm{L}$ : black bars. Values are expressed as mean $\pm \mathrm{SD}(n=3)$. Statistical analyses: ANOVA followed by Tukey's post hoc test. Different letters mean significant differences $(p<0.05)$ contaminated water containing 10 and $50 \mu \mathrm{g} \mathrm{MC}-\mathrm{LR} / \mathrm{L}$. The concentration detected in carrots by ELISA was $5.23 \pm 0.47 \mathrm{ng}$ MC eq./g FW. However, no toxin was detected by LC-ESIMS/MS. These differences may reflect the different principles that characterize these methods and respective LODs. Järvenpää et al. (2007) also reported different toxin concentrations in Sinapis alba and Brassica oleracea, after quantification by LC-MS/MS and ELISA. ELISA non-specifically detects, besides MC-LR, other chemical forms of the molecule that contains the amino acid ADDA. On the other hand, LCESI-MS/MS specifically detects MC-LR and other toxin congeners, following the analysis of the correspondent analytical standard. MC conjugation products with glutathione, cysteine-glycine, and cysteine have been suggested by Metcalf et al. (2000) and Pflugmacher et al. (2001). Furthermore, toxicity assessment of the conjugates, in comparison to MC-LR, indicated a reduction according to mouse bioassay. In vitro protein phosphatase inhibition assay indicated that toxin conjugates possessed approximately 3-9-fold lower toxicity than the parent MC-LR (Metcalf et al., 2000). Indeed, ELISA is not a selective method and potentially quantifies every MC variant that contains the amino acid ADDA, the target of the antibody system of the assay. Despite these differences, both methods are currently used for monitoring MCs contamination in drinking waters and food. The results thus evidence a low contamination of carrots with MC-LR.

The detection of MCs in crops by ELISA has already been reported by several authors (McElhiney et al., 2001; Chen et al., 2004; Peuthert et al., 2007; Crush et al., 2008; Chen et al., 2010). Järvenpää et al. (2007), for instance, were able to detect between 4.1 and $4.9 \mathrm{ng} \mathrm{MC}$ eqs./g FW in roots of $S$. alba and B. oleracea after exposing the plants to Anabaena extract containing $10 \mu \mathrm{g}$ total MCs/L (33\% MCLR) during 19 and 20 days, respectively. The exposure of some horticultural species to a cyanobacterial extract containing $5 \mu \mathrm{g} \mathrm{MC}-\mathrm{LR} / \mathrm{L}$ for $24 \mathrm{~h}$ led to the detection of high MC levels in roots (13.1 to $127.0 \mathrm{ng} \mathrm{MC}$ eq./g root FW) (Peuthert et al., 2007). However, this was a hydroponic study, which could potentiate the bioavailability of the toxin compared to the studies performed in soil.

The exposure of root vegetable Raphanus sativus to contaminated water from underground wells with $0.3-1.8 \mu \mathrm{g} / \mathrm{L}$ total MCs resulted in the detection of $360 \mathrm{ng} \mathrm{Mc} \mathrm{eq./g} \mathrm{FW} \mathrm{in}$ the plant roots (Mohamed and Shehri, 2009), a considerably high value taking into account the low toxin concentration in the irrigation water. A possible explanation of the difference observed in the toxin accumulation between this former and the present study could be speculated from the total toxin administered (TTA) to the plants. In the case that $R$. sativus was exposed for a longer period to the toxin (the total period of the exposure is not referred in the study), the corresponding TTA for that period of exposure could have been comparatively higher and potentiate toxin uptake and accumulation in 
$R$. sativus. TTA can be expressed as the amount of toxin administered per unit of fresh biomass of plant roots (ng MC$\mathrm{LR} / \mathrm{g}$ root $\mathrm{FW}$ ). In the present study, TTA was $1635.4 \mathrm{ng} \mathrm{MC}$ $\mathrm{LR} / \mathrm{g}$ root $\mathrm{FW}$ after 28 days of exposure (2 irrigations per week) to $50 \mu \mathrm{g} \mathrm{MC-LR/L}$. It is therefore important to report the total amount of toxin that plants are exposed (i.e., TTA) for a thorough experiment comparison which will aid in the understanding of the factors underlying toxin accumulation.

Bioconcentration factor (BCF) is the parameter often used to estimate bioaccumulation. It is calculated by the ratio between the concentration of the contaminant in the exposed organism and concentration in the environment; hence, values superior to 1 indicate effective bioaccumulation (Trap, 2009). In this study, the BCF, based on ELISA results, was 0.043 , meaning that there is no bioaccumulation of MC-LR in roots of D. carota.

Understanding toxin bioaccumulation also requires the knowledge of the mechanism of uptake and transport at the root level and throughout the plant. In mammals, cellular MCLR internalization is made by specific bile acid transporters (organic anion transport proteins - OATPs) (Fischer et al., 2005); however, plants do not express homologous proteins and no other potential MC-LR transporter proteins were identified so far leaving unsolved the mechanism of MC-LR uptake. Important to note that MC-LR bioaccumulation seems to be determined by genetic factors since differences in bioaccumulation were found between species and crop varieties (Chen et al., 2004, Peuthert et al., 2007, Crush et al., 2008, Saqrane et al., 2009). Moreover, other factors may also influence considerably toxin accumulation as for instance the bioavailability of the toxin in soil (Chen et al., 2006). Soil effects may comprise also the interaction of soil minerals and organic nutrients with the uptake of MC-LR.

Based on the potential for human health risks, the World Health Organization (WHO) established a tolerable daily intake (TDI) of $0.04 \mu \mathrm{g}$ MC-LR/kg body weight (BW) (WHO, 1999). If a 60-kg person consuming $100 \mathrm{~g}$ (FW) of contaminated carrots, as reported in this work (5.23 ng MC eq./g carrot $\mathrm{FW}$ ), the corresponding toxin intake would be $0.01 \mu \mathrm{g}$ MC-LR/kg BW), i.e., below the TDI established by WHO. Based on these results, the reported toxin concentration in carrots does not seem to represent a health risk for consumers. However, careful should be taken on this consideration, which should take into account the adopted human diet and the vulnerability of groups of risk (e.g., children).

\section{Bioavailability of MC-LR in soil}

The MC-LR bioavailability in the soil has been poorly studied. In this work, an environmentally relevant exposure scenario, where plants were grown in soil and irrigated with $\mathrm{MC}$ LR contaminated water was attained, allowing also estimating the bioavailability of the toxin in soil. The toxin detected in soil after its contamination with $50 \mu \mathrm{g}$ MC-LR/L for 28 days was $171.47 \pm 6.76 \mathrm{ng}$ MC eq./g soil FW, measured by ELISA, and $112.44 \pm 32.60 \mathrm{ng}$ MC-LR/g soil FW measured by LCESI-MS/MS. The LC-MS analysis of MC-LR in soil is presented in online resource supplementary material (Figure S2 and S3). Likewise, the quantification of MC-LR in plant tissues, here we also registered different toxin concentrations from the two quantification methods. Again, the highest toxin concentration was detected with ELISA denoting, in addition to MC-LR, a probable presence of MC metabolites in soil, caused eventually by the degradation of the toxin. Indeed, various ubiquitous bacteria of soil, such as Arthrobacter sp., Brevibacterium sp., Rhodococcus sp., and Sphingomonas sp., appear to be capable to degrade MC (Bourne et al., 2001; Manage et al., 2009). The soil, therefore, seems to play an important role in the subsequent availability of MC-LR for plants, with the adsorption and/or degradation of a significant fraction of the toxin administered. Taking in consideration that the total amount of toxin added to the soil along the experiment was approximately $213.33 \mathrm{ng} \mathrm{MC}-\mathrm{LR} / \mathrm{g}$ soil $\mathrm{FW}$, the MC-LR estimated by LC-ESI-MS/MS (112.44 $\pm 32.60 \mathrm{ng}$ MC-LR/g soil FW) represented only $52.71 \%$ of the total of the toxin potentially present in soil, meaning that the toxicity of the soil was reduced to near half of its potential at the end of the experiment. In this regard, it can be suggested that the plant culture systems such as hydroponics that do not require soil or other natural plant substrates may increase the bioavailability of the toxin and hence potentiate its accumulation in the plants, as it was suggested by several studies (McElhiney et al., 2001; Chen et al., 2004; Peuthert et al., 2007; Crush et al., 2008; Mohamed and Al Shehri, 2009; Saqrane et al., 2009; Chen et al., 2010). In this study, the absence of MC-LR bioaccumulation in carrot roots can be explained by the reduced bioavailability of the toxin in soil. Large differences may exist with respect to the half-life of MC-LR and its bioavailability in soil, which can be explained by the differences in the physical and chemical characteristics of soils and microbial activity. Chen et al. (2006) denoted that MCs are pollutants of high mobility in soil, indicating that the mobility is mainly related with the soil clay content, having the soils with a high clay and/or organic carbon contents a high adsorption coefficients of toxins. In our case, we have a soil with a high organic carbon content $(>70 \%$, as stated in material and methods section) which can explain why only half of the applied toxin could be quantified in the soil at the end of the experiment. Chen et al. (2006) also observed that the toxin could persist in agricultural soils for relatively long periods, with a half-life in the range of 6 to 18 days. Corbel et al. (2014b), however, reported half-life of ${ }^{14} \mathrm{C}-\mathrm{MC}$-LR superior to 60 days in agricultural soil. Regarding the investigation of toxin contamination in plant-soil systems, it is therefore recommended to know, in addition to TTA, the toxin bioavailability and toxin half-life for each type of soil utilized. 


\section{Conclusions}

According to our knowledge, this is the first work reporting the effects of MC-LR-contaminated water on carrots, in which growth, photosynthesis, mineral and vitamin content and toxin accumulation were investigated. Exposure of carrots to low concentrations of MC-LR does not seem to adversely affect plant growth and photosynthesis, within the considered exposure time. However, we hypothesize that prolonged exposure to water containing $50 \mu \mathrm{g} \mathrm{MC}-\mathrm{LR} / \mathrm{L}$ may have a potential negative effect on root growth. The alterations reported in the content of vitamins (ascorbic acid) and minerals $(\mathrm{Mg}$, $\mathrm{Na}, \mathrm{K}, \mathrm{Fe}, \mathrm{Zn}, \mathrm{Mo}$, and $\mathrm{P}$ ) in carrots as a result of the presence of MC-LR in the irrigation water suggest that this type of contamination has implications on the nutritional value of carrots. The potential presence of MC-LR was also observed in carrot roots, although no bioaccumulation was registered. This result calls for the necessity to extend the studies to other environmental scenarios that can potentiate the uptake and accumulation of this toxin. In the future, it will be also important to extend the present study to other agricultural crops for a thorough risk assessment of the use of contaminated water in agriculture. Furthermore, metabolic profiling of the bioactive compounds present in the contaminated water would help to determine which other bioactive metabolites are present in the water and the main role of MC-LR on the observed symptoms.

Acknowledgments This research was partially supported by the European Regional Development Fund (ERDF) through the COMPETE-Operational Competitiveness Programme and national funds through FCT-Foundation for Science and Technology under the project PEst-C/MAR/LA0015/2013 and by Porto University under the framework of the project IJUP2011_3. A. Campos work is supported by a post-doctoral grant (SFRH/BPD/103683/2014) from FCT.

\section{References}

Aboal M, Puig MA (2005) Intracellular and dissolved microcystin in reservoirs of the river Segura basin, Murcia, SE Spain. Toxicon 45(4):509-518. doi:10.1016/j.toxicon.2004.12.012

Ahamad MN, Saleemullah M, Shah HU, Khalil IA, Saljoqi AUR (2007) Determination of beta content in fresh vegetables using high performance liquid chromatography. Sarhad Journal of Agriculture 23(3): $767-770$

Azevedo CC, Azevedo J, Osório H, Vasconcelos V, Campos A (2014) Early physiological and biochemical responses of rice seedlings to low concentration of microcystin-LR. Ecotoxicology 23(2):107121. doi:10.1007/s10646-013-1156-8
Bibo L, Yan G, Bangding X, Jiantong L, Yongding L (2008) A laboratory study on risk assessment of microcystin-RR in cropland. J Environ Manag 86(3):566-574. doi:10.1016/j.jenvman.2006.12.040

Bittencourt-Oliveira Mdo C, Cordeiro-Araújo MK, Chia MA, ArrudaNeto JD, de Oliveira ÊT, dos Santos F (2016) Lettuce irrigated with contaminated water: photosynthetic effects, antioxidative response and bioaccumulation of microcystin congeners. Ecotoxicol Environ Saf 128:83-90. doi:10.1016/j.ecoenv.2016.02.014

Bláhová L, Adamovský O, Kubala L, Švihálková Šindlerová L, Zounková R, Bláha L (2013) The isolation and characterization of lipopolysaccharides from Microcystis aeruginosa, a prominent toxic water bloom forming cyanobacteria. Toxicon 76:187-196. doi:10.1016/j.toxicon.2013.10.011

Bourne DG, Riddles P, Jones GJ, Smith W, Blakeley RL (2001) Characterization of a gene cluster involved in bacterial degradation of the cyanobacterial toxin microcystin-LR. Environ Toxicol 16(6): 523-534. doi:10.1002/tox.10013

Burýsková B, Hilscherová K, Babica P, Vrsková D, Marsálek B, Bláha L (2006) Toxicity of complex cyanobacterial samples and their fractions in Xenopus laevis embryos and the role of microcystins. Aquat Toxicol 80(4):346-354. doi:10.1016/j.aquatox.2006.10.001

Chen J, Song L, Dai J, Gan N, Zhili L (2004) Effects of microcystins on the growth and the activity of superoxide dismutase and peroxidade of rape (Brassica napus L.) and rice (Oryza sativa L.). Toxicon 43(4):393-400. doi:10.1016/j.toxicon.2004.01.011

Chen W, Song L, Gan N, Li L (2006) Sorption, degradation and mobility of microcystins in Chinese agriculture soils: risk assessment for groundwater protection. Environ Pollut 144(3):752-758. doi:10.1016/j.envpol.2006.02.023

Chen J, Dai J, Zhang H, Wang C, Zhou G, Han Z, Liu Z (2010) Bioaccumulation of microcystin and its oxidative stress in the apple (Malus pumila). Ecotoxicology 19(4):796-803. doi:10.1007 /s10646-009-0456-5

Chen J, Han FX, Wang F, Zhang HQ, Shi ZQ (2012) Accumulation and phytotoxicity of microcystin-LR in rice (Oryza sativa). Ecotoxicol Environ Saf 76(2):193-199. doi:10.1016/j.ecoenv.2011.09.022

Corbel S, Mougin C, Bouaïcha N (2014a) Cyanobacterial toxins: modes of actions, fate in aquatic and soil ecosystems, phytotoxicity and bioaccumulation in agricultural crops. Chemosphere 96:1-15. doi:10.1016/j.chemosphere.2013.07.056

Corbel S, Bouaïcha N, Mougin C (2014b) Dynamics of the toxic cyanobacterial microcystin-leucine-arginine peptide in agricultural soil. Environ Chem Lett 12(4):535-541. doi:10.1007/s10311-014$0482-2$

Corbel S, Bouaïcha N, Nélieu S, Mougin C (2015) Soil irrigation with water and toxic cyanobacterial microcystins accelerates tomato development. Environ Chem Lett 13(4):447-452. doi:10.1007 /s10311-015-0518-2

Crush JR, Briggs LR, Sprosen JM, Nichols SN (2008) Effect of irrigation with lake water containing microcystins on microcystin content and growth of ryegrass, clover, rape, and lettuce. Environ Toxicol 23(2): 246-252. doi:10.1002/tox.20331

Dawson RM (1998) The toxicology of microcystins. Toxicon 36(7):953962. doi:10.1016/S0041-0101(97)00102-5

Duy TN, Lam PKS, Shaw GR, Connell DW (2000) Toxicology and risk assessment of freshwater cyanobacterial (blue-green algal) toxins in water. Rev Environ Contam Toxicol 163:113-186. doi:10.1007 /978-1-4757-6429-1_3

El Khalloufi F, Oufdou K, Lahrouni M, El Ghazali I, Saqrane S, Vasconcelos V, Oudra B (2011) Allelopatic effects of cyanobacteria extracts containing microcystins on Medicago sativa-rhizobia symbiosis. Ecotoxicol Environ Saf 74(3):431-438. doi:10.1016/j. ecoenv.2010.10.006

El Khalloufi F, El Ghazali I, Saqrane S, Oufdou K, Vasconcelos V, Oudra B (2012) Phytotoxic effects of a natural bloom extract containing 
microcystins on Lycopersicon esculentum. Ecotoxicol Environ Saf 79:199-205. doi:10.1016/j.ecoenv.2012.01.002

Figueiredo DR, Azeiteiro UM, Esteves SM, Gonçalves FJM, Pereira JM (2004) Microcystin-producing blooms - a serious global public health issue. Ecotoxicol Environ Saf 59(2):151-163. doi:10.1016 j.ecoenv.2004.04.006

Fischer WJ, Altheimer S, Cattori V, Meier PJ, Dietrich DR, Hagenbuch B (2005) Organic anion transporting polypeptides expressed in liver and brain mediate uptake of microcystin. Toxicol Appl Pharmacol 203:257-263. doi:10.1016/j.taap.2004.08.012

Freitas M, Azevedo J, Pinto E, Neves J, Campos A, Vasconcelos V (2015) Effects of microcystin-LR, cylindrospermopsin and a microcystin-LR/cylindrospermopsin mixture on growth, oxidative stress and mineral content in lettuce plants (Lactuca sativa L.). Ecotoxicol Environ Saf 116:59-67. doi:10.1016/j. ecoenv.2015.02.002

Fridovich I, Handler P (1961) Detection of free radicals generated during enzymic oxidation by the initiation of sulphite oxidation. J Biol Chem 236:1836-1840

Funari E, Testai E (2008) Human health risk assessment related to cyanotoxins exposure. Crit Rev Toxicol 38(2):97-125. doi:10.1080/10408440701749454

Gehringer MM, Kewada V, Coates N, Downing TG (2003) The use of Lepidium sativum in a plant bioassay system for the detection of microcystin-LR. Toxicon 41(7):871-876. doi:10.1016/S0041-0101 (03)00049-7

Gurbuz F, Metcalf JS, Karahan AG, Codd GA (2009) Analysis of dissolved microcystins in surface water samples from Kovada Lake, Turkey. Sci Total Environ 407(13):4038-4046. doi:10.1016/j. scitotenv.2009.02.039

Hardy FJ, Johnson A, Hamel K, Preece E (2015) Cyanotoxin bioaccumulation in freshwater fish, Washington State, USA. Environ Monit Assess 187(11):667. doi:10.1007/s10661-015-4875-x

Hitzfeld BC, Höger SJ, Dietrich DR (2000) Cyanobacterial toxins: removal during drinking water treatment and human risk assessment. Environ Health Perspect 108(S1):113-122. doi:10.2307/3454636

Huang X, Chen L, Liu W, Qiao Q, Wu K, Wen J, Huang C, Tang R, Zhang $X$ (2015) Involvement of oxidative stress and cytoskeletal disruption in microcystin-induced apoptosis in CIK cells. Aquat Toxicol 165:41-50. doi:10.1016/j.aquatox.2015.05.009

IARC. (2010). Ingested nitrate and nitrite, and cyanobacterial peptide toxins, IARC Monogr Eval Carcinog Risks Hum Suppl, 94, Lyon, France. pp 327-412. ISSN 1014-711X. Available in: http://monographs.iarc.fr/ENG/Monographs/suppl7/suppl7.pdf

Ismail A, Sook Fun C (2003) Determination of vitamin C, $\beta$-carotene and riboflavin contents in five green vegetables organically and conventionally grown. Malays J Nutr 9(1):31-39

Järvenpää S, Lundberg-Niinistö C, Spoof L, Sjövall O, Tyystjärvi E, Meriluoto J (2007) Effects of microcystins on broccoli and mustard, and analysis of accumulated toxin by liquid chromatography-mass spectrometry. Toxicon 49(6):865-874. doi:10.1016/j. toxicon.2006.12.008

Keutgen AJ, Pawelzic E (2007) Modifications of strawberry fruit antioxidant pools and fruit quality under $\mathrm{NaCl}$ stress. J Agric Food Chem 55(10):4066-4072. doi:10.1021/jf070010k

Kótai, J. (1972). Instructions for preparation of modified nutrient solution Z8 for algae. Norwegian Institute for Water Research, B-11/69

Lahrouni M, Oufdou K, El Khalloufi F, Baz M, Lafuente A, Dary M, Pajuelo E, Oudra B (2013) Physiological and biochemical defense reactions of Vicia faba L.-rhizobium symbiosis face to chronic exposure to cyanobacterial bloom extract containing microcystins. Environ Sci Pollut Res Int 20(8):5405-5415. doi:10.1007/s11356013-1535-y

Li TQ, Tao Q, Di ZZ, Lu F, Yang XE (2014) Effect of elevated CO2 concentration on photosynthetic characteristics of hyperaccumulator
Sedum alfredii under cadmium stress. J Integr Plant Bio 57(7):653660. doi:10.1111/jipb.12307

Manage PM, Edwards C, Singh BK, Lawton LA (2009) Isolation and identification of novel microcystin-degrading bacteria. Appl Environ Microbiol 75(21):6924-6928. doi:10.1128/AEM.01928-09

Maxwell K, Johnson N (2000) Cholorophyll fluorescence - a practical guide. J Exp Bot 51(345):659-668. doi:10.1093/jexbot/51.345.659

Mazid M, Khan TA, Khan ZH, Quddusi S, Mohammad F (2011) Occurrence, biosynthesis and potentialities of ascorbic acid in plants. Int. J. Pl.An and Env. Sci 1(2):167-184

McElhiney J, Lawton LA, Leifert C (2001) Investigations into the inhibitory effects of microcystins on plant growth, and the toxicity of plant tissues following exposure. Toxicon 39(9):1411-1420. doi:10.1016/S0041-0101(01)00100-3

Metcalf JS, Beattie KA, Pflugmacher S, Codd GA (2000) Immunocrossreactivity and toxicity assessment of conjugation products of the cyanobacterial toxin, microcystin-LR. FEMS Microbiol Lett 189(2):155-158. doi:10.1111/j.1574-6968.2000.tb09222.x

Mohamed Z, Al Shehri AM (2009) Microcystins in groundwater wells and their accumulation in vegetable plants irrigated with contaminated waters in Saudi Arabia. J Hazard Mater 172(1):310-315. doi:10.1016/j.jhazmat.2009.07.010

Murphy J, Riley J (1962) A modified single solution method for the determination of phosphate in natural waters. Anal Chim Acta 27: 31-36. doi:10.1016/S0003-2670(00)88444-5

Nasri H, El Herry S, Bouaïcha N (2008) First reported case of turtle deaths during a toxic Microcystis spp. bloom in Lake Oubeira Algeria. Ecotoxicol Environ Saf 71(2):535-544. doi:10.1016/j. ecoenv.2007.12.009

Ni, W., Zhang, J., Luo Y. (2015). Microcystin accumulation in bighead carp (Aristichthys nobilis) during a Microcystis-dominated bloom and risk assessment of the dietary intake in a fish pond in China. Environ Sci Pollut Res Int:1-9. doi: 10.1007/s11356-015-4974-9

Noctor G, Foyer CH (1998) Ascorbate and glutathione. Keeping active oxygen under control. Annu Rev Plant Physiol Plant Mol Biol 49: 249-279. doi:10.1146/annurev.arplant.49.1.249

O'Neil JM, Davis TW, Burford MA, Gobler CJ (2012) The rise of harmful cyanobacteria blooms: the potential roles of eutrophication and climate change. Harmful Algae 14:313-334. doi:10.1016/j. hal.2011.10.027

Paerl HW, Paul VJ (2012) Climate change: links to global expansion of harmful cyanobacteria. Water Res 46:1349-1363. doi:10.1016/j. watres.2011.08.002

Pereira S, Saker M, Vale M, Vasconcelos V (2009) Comparison of sensitivity of grasses (Lolium perenne L. and Festuca rubra L.) and lettuce (Lactuca sativa L.) exposed to water contaminated with microcystins. Bull Environ Contam Toxicol 83(1):81-84. doi:10.1007/s00128-009-9763-z

Pereira AL, Monteiro B, Azevedo J, Campos A, Osório H, Vasconcelos V (2015) Effects of the naturally-occurring contaminant microcystins on the Azolla filiculoides-Anabaena azollae symbiosis. Ecotoxicol Environ Saf 118:11-20. doi:10.1016/j.ecoenv.2015.04.008

Peuthert A, Chakrabarti S, Pflugmacher S (2007) Uptake of microcystinsLR and -LF (cyanobacterial toxins) in seedlings of several important agricultural plant species and the correlation with cellular damage (lipid peroxidation). Environ Toxicol 22:436-442. doi:10.1897/05615R.1

Pflugmacher S (2002) Possible allelopathic effects of cyanotoxins, with reference to microcystin-LR, in aquatic ecosystems. Environ Toxicol 17(4):407-413. doi:10.1002/tox.10071

Pflugmacher S, Wiegand C, Beattie KA, Krause E, Steinberg CEW, Codd GA (2001) Uptake, effects, and metabolism of cyanobacterial toxins in the emergent reed plant Phragmites australis (cav.) trin. ex steud. Environ Toxicol Chem 20(4):846-852. doi:10.1002 /etc.5620200421 
Pflugmacher S, Jung K, Lundvall L, Neumann S, Peuthert A (2006) Effects of cyanobacterial toxins and cyanobacterial cell-free crude extract on germination of alfalfa (Medicago sativa) and induction of oxidative stress. Environ Toxicol Chem 25(9):2381-2387. doi:10.1897/05-615R.1

Pflugmacher S, Aulhorn M, Grimm B (2007a) Influence of a cyanobacterial crude extract containing microcystin-LR on the physiology and antioxidative defence systems of different spinach variants. New Phytol 175(3):482-489. doi:10.1111/j.14698137.2007.02144.x

Pflugmacher S, Hofmann J, Hübner B (2007b) Effects on growth and physiological parameters in wheat (Triticum aestivum L.) grown in soil and irrigated with cyanobacterial toxin contaminated water. Environ Toxicol Chem 26(12):2710-2716. doi:10.1897/07-145.1

Pichardo S, Pflugmacher S (2011) Study of the antioxidant response of several bean variants to irrigation with water containing MC-LR and cyanobacterial crude extract. Environ Toxicol 26(3):300-306. doi:10.1002/tox.20622

Pinheiro C, Azevedo J, Campos A, Loureiro S, Vasconcelos V (2013) Absence of negative allelopathic effects of cylindrospermopsin and microcystin-LR on selected marine and freshwater phytoplankton species. Hydrobiologia 705(1):27-42. doi:10.1007/s10750-012-1372-x

Pinto E, Almeida AA, Aguiar AA, Ferreira IM (2014) Changes in macrominerals, trace elements and pigments content during lettuce (Lactuca sativa L.) growth: influence of soil composition. Food Chem 152:603-611. doi:10.1016/j.foodchem.2013.12.023

Prieto A, Campos A, Cameán A, Vasconcelos V (2011) Effects on growth and oxidative stress status of rice plants (Oryza sativa) exposed to two extracts of toxin-producing cyanobacteria (Aphanizomenon ovalisporum and Microcystis aeruginosa). Ecotoxicol Environ Saf 74(7):1973-1980. doi:10.1016/j.ecoenv.2011.06.009

Ramanan S, Tang J, Velayudhan A (2000) Isolation and preparative purification of microcystin variants. J Chromatogr A 883(1-2):103112. doi:10.1016/S0021-9673(00)00378-2

Rao PVL, Gupta N, Bhaskar ASB, Jayaraj R (2002) Toxins and bioactive compounds from cyanobacteria and their implications on human health. J Environ Biol 3(23):215-224

Romero-Oliva C-S, Contardo-Jara V, Block T, Pflugmacher S (2014) Accumulation of microcystin congeners in different aquatic plants and crops - a case study from lake Amatitlán, Guatemala. Ecotoxicol Environ Saf 102:121-128. doi:10.1016/j. ecoenv.2014.01.031

Sadler T, von Elert E (2014) Physiological interaction of Daphnia and Microcystis with regard to cyanobacterial secondary metabolites. Aquat Toxicol 156:96-105. doi:10.1016/j.aquatox.2014.08.003

Saqrane S, Ghazali IE, Oudra B, Bouarab L, Vasconcelos V (2008) Effect of cyanobacteria producing microcystins on seed germination and seedling growth of several agricultural plants. J Environ Sci Health B 43(5):443-451. doi:10.1080/10934520701796192
Saqrane S, Ouahid Y, El Ghazali I, Oudra B, Bouarab L, del Campo FF (2009) Physiological changes in Triticum durum, Zea mays, Pisum sativum and Lens esculenta cultivars, caused by irrigation with water contaminated with microcystins: a laboratory experimental approach. Toxicon 53(7-8):786-796. doi:10.1016/j. toxicon.2009.01.028

Singh DP, Beloy J, McInerney JK, Day L (2012) Impact of boron, calcium and genetic factors on vitamin $\mathrm{C}$, carotenoids, phenolic acids, anthocyanins and antioxidant capacity of carrots (Daucus carota). Food Chem 132(3):1161-1170. doi:10.1016/j. foodchem.2011.11.045

Spoof L, Vesterkvist P, Lindholm T, Meriluoto J (2003) Screening for cyanobacterial hepatotoxins, microcystins and nodularin in environmental water samples by reversed-phase liquid chromatographyelectrospray ionisation mass spectrometry. J Chromatogr A 1020(1):105-119. doi:10.1016/S0021-9673(03)00428-X

Stüven J, Pflugmacher S (2007) Antioxidative stress response of Lepidium sativum due to exposure to cyanobacterial secondary metabolites. Toxicon 50(1):85-93. doi:10.1016/j.toxicon.2007.02.019

Trapp S. (2009). Bioaccumulation of polar and ionizable compounds in plants. Ecotoxicology Modeling, Emerging Topics in Ecotoxicology: Principles, Approaches and Perspectives 2, J. Devillers (ed.), Springer Science + Business Media, LLC. doi: 10.1007/978-1-4419-0197-2 11

Ueno Y, Nagata S, Tsutsumi T, Hasegawa A, Watanabe MF, Park HD, Chen GC, Chen G, Yu SZ (1996) Detection of microcystins, a bluegreen algal hepatotoxins, in drinking water sampled in Haimen and Fusui, endemic areas of primary liver cancer in China, by highly sensitive immunoassay. Carcinogenesis 17(6):1317-1321. doi:10.1093/carcin/17.6.1317

Vasconcelos VM (1995) Uptake and depuration of the heptapeptide toxin microcystin-LR in Mytilus galloprovincialis. Aquat Toxicol 32: 227-237. doi:10.1016/0166-445X(94)00085-5

WHO (1999) Toxic cyanobacteria in water: a guide to their public health consequences, monitoring and management. In: Bartram J (ed) Chorus I. London and New York, World Health

Yu SZ (1995) Primary prevention of hepatocellular carcinoma. J Gastroenterol Hepatol 10(6):674-682. doi:10.1111/j.14401746.1995.tb01370.x

Zegura B, Straser A, Filipič M (2011) Genotoxicity and potential carcinogenicity of cyanobacterial toxins - a review. Mutat Res 727:16 41. doi:10.1016/j.mrrev.2011.01.002

Zhou L, Yu H, Chen K (2002) Relationship between microcystin in drinking water and colorectal cancer. Biomed Environ Sci 15(2): 166-171

Zhou M, Tu WW, Xu J (2015) Mechanisms of microcystin-LR-induced cytoskeletal disruption in animal cells. Toxicon 101:92-100. doi:10.1016/j.toxicon.2015.05.005 